\title{
Reconocimiento automático de patrones y características de las imágenes de los cultivos como alternativa para el desarrollo agrícola
}

\section{Automatic recognition of patterns and characteristics of crop images as an alternative for agricultural development}

\author{
Juan José Bedolla Solano ${ }^{1}$ \\ Eleazar Pacheco Salazar ${ }^{2}$ \\ Silvestre Bedolla Solano ${ }^{3}$
}

Fecha de recepción: 13-2-2019

Fecha de aprobación: 25-8-2019

\begin{abstract}
Resumen
Este trabajo describe una metodología para identificar los patrones o características de los cultivos, mediante el empleo de los algoritmos de reconocimiento de la ingeniería del software. Este sistema procesa información referente al progreso de las plantas; para ello, se realizaron comparaciones de imágenes que fueron capturadas usando Vehículos Aéreos No Tripulados VANT/ DRONES como uno de los recursos de las Tecnologías de la Información y Comunicación (TIC), y los objetos contenidos en una Base de Datos que poseen características normales y anormales de diversas plantas como el mango, el limón y la palmera de coco. El procesamiento de datos a través de la aplicación automatizada generó resultados de identificación favorables mediante el reconocimiento automático de los cultivos, ya que se identificaron con el proceso de comparación las imágenes con características normales y anormales.

El proyecto beneficiará principalmente a los agricultores, pues se podrán identificar los riesgos de los sembradíos provocados por las plagas de insectos infecciosos que ingresan a los cultivos (mosquita blanca), además de otras probables anomalías como quemaduras (enfermedad de hoja seca), las cuales podrían obstaculizar el crecimiento óptimo de la planta. Con ello, se podrán tomar decisiones oportunas para atender los riesgos de los cultivos con el apoyo del sistema de reconocimiento.

El tratamiento de información referente al progreso de los sembradíos genera consigo una propuesta innovadora que incorpora las tecnologías con amplias posibilidades para el desarrollo agrícola en las costas de Guerrero, México.

Con la modernización y específicamente el uso de estos sistemas automáticos que administran y difunden la información, se podrán atender de manera oportuna los riesgos de la agricultura y evitar así pérdidas de la cosecha, generando impactos en el desarrollo social, económico y ambiental al atender de manera oportuna los riesgos o peligros presentados en el cultivo.
\end{abstract}

Palabras clave: Agricultura, Desarrollo Sustentable, Tecnología y Sustentabilidad, Recursos Electrónicos, Sistema Automatizado.

1 Doctor en Desarrollo Regional. Profesor Investigador; Carrera de Ingeniería en Sistemas Computacionales del Instituto Tecnológico de Acapulco/TECNOLÓGICO NACIONAL DE MÉXICO, Grupo de Trabajo: Tecnología y Sustentabilidad; e-mail: jjosebedolla@hotmail.com. y jjosebedolla@it-acapulco.edu.mx.

2 Maestra en Ciencias Computacionales, Profesora del Instituto Tecnológico de Acapulco/TECNOLÓGICO NACIONAL DE MÉXICO; Grupo de Trabajo: Tecnología y Sustentabilidad; e-mail: abi_pa65@hotmail.com.

3 Maestro en Ciencias de la Familia. Profesor del Instituto Tecnológico de Acapulco/TECNOLÓGICO NACIONAL DE MÉXICO; Grupo de Trabajo: Tecnología y Sustentabilidad; e-mail: silvestre.bedolla@gmail.com. 


\begin{abstract}
This work describes a methodology to identify the patterns or characteristics of the crops, using the software engineering recognition algorithms. This system processes information regarding the progress of the plants; for this, comparisons were made of images that were captured using VANT / DRONES Unmanned Aerial Vehicles as one of the resources of Information and Communication Technologies (ICT), and the objects contained in a Database that contain normal characteristics and abnormal of various plants such as mango, lemon and coconut palm.

Data processing through the automated application generated favorable identification results through automatic crop recognition, since images with normal and abnormal characteristics were identified with the comparison process.

The project will mainly benefit farmers, since the risks of crops caused by infectious insect pests entering crops (white mosquito) can be identified; In addition to other probable anomalies such as burns (dry leaf disease), which could hinder the optimal growth of the plant. With this, timely decisions can be taken to address crop risks with the support of the recognition system.

The treatment of information regarding the progress of the crops generates an innovative proposal that incorporates technologies with wide possibilities for agricultural development on the coasts of Guerrero, Mexico.

With the modernization and specifically the use of these automatic systems that manage and disseminate the information, the risks of agriculture can be addressed in a timely manner avoiding crop losses; having impacts on social, economic and environmental development by attending in a timely manner the risks or dangers presented in the crop.
\end{abstract}

Keywords: Agriculture, Sustainable Development, Technology and Sustainability, Electronic Resources, Automated System.

\title{
I. Introducción
}

La humanidad se desenvuelve en un amplio contexto, y en cada momento examina diversas formas y alternativas de subsistencia, que repercuten en mejores condiciones de vida, apoyándose en recursos que le permita facilitar los trabajos o tareas que se emprenden en cada una de las actividades de producción y que aseguren la supervivencia. En los últimos tiempos, las actividades que son emprendidas por la sociedad, y especialmente el sector empresarial, se han apoyado en su mayoría en las Tecnologías de la Información y Comunicación (TIC), ya que se encuentran dirigidas a la productividad, rentabilidad y la generación de economías.

Las Tecnologías de la Información y Comunicación desempeñan un papel imprescindible en la realización de las actividades o tareas que se llevan a cabo por la sociedad. La incorporación de estas herramientas se apoya también en otros recursos electrónicos y procesos que les permite facilitar los trabajos o tareas que se emprenden en cada una de las actividades de producción o dinámicas para la ejecución de las labores.
El desarrollo tecnológico como un avance imparable y desmedido ha impactado de manera positiva a nivel mundial, y ha buscado mejorar la productividad concentrando la atención en los procesos de emprendimiento, principalmente del sector empresarial. Pero también se tienen impactos, en otros ámbitos, como la salud, la educación, las actividades cotidianas del hogar, la agricultura y en los últimos tiempos con gran interés, la dimensión ambiental o ecológica.

Las prácticas agrícolas que se realizan en una determinada región se desarrollan de acuerdo con los métodos y costumbres que plantean el seguimiento de las acciones en los modelos de producción que llevan a cabo los agricultores, las cuales suelen ser específicas y dirigidas con base en los cultivos de cierta comunidad o región. El Plan de Desarrollo del Gobierno Federal de México 20122018, instrumenta un programa nacional que promueva buenas prácticas de manejo del territorio para frenar la degradación y erosión del suelo, fortalecer la gobernanza, impulsar el manejo forestal comunitario sustentable y evitar la tala ilegal, incendios y plagas, en beneficio de todos los mexicanos, en particular de las comunidades 
indígenas. Se señala, también, en una línea de acción, orientar la investigación y desarrollo tecnológico hacia la generación de innovaciones que aplicadas al sector agroalimentario eleve la productividad y competitividad.

Los nuevos modelos de producción apoyados de la modernización e innovación con tecnologías emergentes de la información y comunicación desempeñan un papel interesante e imprescindible. En este contexto, se han desarrollado sistemas automatizados innovadores con resultados óptimos para todos los sectores de la humanidad, como el económico, el social y el ecológico o ambiental. En el sector agrícola, se han emprendido desde modelos y sistemas que buscan resolver escenarios de producción para la mejora del cultivo e incremento del desarrollo favorable de las plantas. En los últimos tiempos, se continúa con el avance de los sistemas tecnológicos que aportan al cultivo y que han impactado en el sector agrícola, tal es el caso de los sistemas de reconocimiento automatizado que se enfocan en el tratamiento de información de los sembradíos para detección de plagas como aquellas provocadas por la mosquita blanca y enfermedades de mancha de la hoja, y que de alguna u otra manera, obstaculizan el crecimiento y desarrollo favorable.

El procesamiento digital de imágenes es una herramienta ampliamente utilizada en la automatización de procesos industriales, debido a que presenta confiabilidad, eficacia y rapidez en el procesamiento (Cáceres, 2015). La industria agrícola ha comenzado a utilizar este tipo de tecnología para monitorear aspectos relevantes de los cultivos (Yan et al., 2009; Noda et al., 2006; y Husin et al., 2012).

El sistema de reconocimiento automático, que se describe, realiza la comparación de las imágenes de los cultivos que fueron capturadas con el dron y los objetos contenidos en una base de datos, la cual contiene las imágenes de diversas plantas con características de plantas tanto normales como anormales. Las imágenes de los cultivos utilizados para las pruebas preliminares en el proyecto fueron el mango, el limón y la palmera de coco, dichas imágenes fueron captadas con el dron para proceder enseguida con el proceso de comparación a través de la aplicación automatizada y generar de manera automática los resultados de identificación de los patrones y características del cultivo. Las comparaciones de las imágenes son realizadas de manera automática, mediante algoritmos y aplicaciones, que procesan los datos para generar consigo un porcentaje de reconocimiento de patrones de los objetos. La información que se genera con el sistema de reconocimiento se registra en la base de datos para su tratamiento posterior y se generan los reportes que serán analizados y descritos en un futuro para la toma de decisiones.

El reconocimiento automático de patrones y características en las imágenes de los cultivos es una novedad provechosa utilizada para identificar los riesgos o enfermedades; por consiguiente, se propone como una alternativa para el desarrollo de las plantaciones agrícolas.

Este trabajo tiene como propósito identificar, mediante un sistema automatizado, las características o patrones de las plantas de un sembradío que permitan informar de manera oportuna los riesgos que puedan obstaculizar el desarrollo favorable de los cultivos, además de presentar una propuesta estratégica que incorpora las tecnologías innovadoras para el desarrollo en el sector agrícola para las costas de Guerrero, México.

\section{Razonamiento analítico}

La agricultura como uno de los pilares de subsistencia y motor del desarrollo económico de las regiones, presenta síntomas importantes que se observan en la producción del sector agrícola. Entre los cultivos que hacen presencia en las costas del estado de Guerrero, y que ha visto deteriorada su producción, se mencionan el limón, el mango y la palmera de coco. La baja producción de estos cultivos se ha presentado con mayor relevancia en la región de Acapulco y la Costa Chica de Guerrero. También, se observan diversos eventos climáticos que afectan al medio ambiente y a la sociedad, como la contaminación de suelo, agua y aire, y otros factores que están impactando en el calentamiento global. Los eventos climáticos extremos traen como consecuencia grandes pérdidas económicas, daños a la salud y, en muchos casos, desastres y fallecimientos (Murray y Murray, 2012). En las regiones de Acapulco y la Costa Chica se han presentado 
fenómenos naturales como huracanes y los ciclones,que han afectado principalmente al sector agrícola y la sociedad. Tal es el caso de los huracanes Paulina en 1997 y el MAX en 2017, que produjeron importantes desastres, como inundaciones, muertes de personas y afectaciones importantes en la agricultura.

El proceso de desarrollo de los vegetales radica principalmente en la variable del clima o temperatura de una región, pero también tiene que ver con los factores del agua, suelo, aire, riesgos por fenómenos naturales, entre otras afectaciones. Como consecuencia de estos fenómenos naturales, los cultivos de las plantas de limón, el mango y la palmera de coco presentaron afectaciones importantes como plagas de la mosquita blanca y enfermedades de hojas secas, lo que trajo como consecuencia obstaculizar el desarrollo favorable de estos cultivos, y por consiguiente, la baja producción de la cosecha. Las consecuencias del desequilibrio y cambio climático están afectando el ciclo de vida de desarrollo de los cultivos. En estos desequilibrios, se perciben también consecuencias de deterioro ambiental, al no ser atendidas por la sociedad en generar las dimensiones del desarrollo sustentable.

El trabajo "reconocimiento automático de patrones y características de las imágenes de los cultivos" ofrece una alternativa para el desarrollo agrícola, ya que se podrán identificar los riesgos por plagas o enfermedades en las plantas mediante el uso de las tecnologías. Este sistema ofrece alternativas para la generación y tratamiento de información para la toma de decisiones, lo que permite atender oportunamente los riesgos en el progreso y la productividad de las plantas. Con la modernización tecnológica y el desarrollo de los sistemas automatizados, que incorporan recursos electrónicos como la aplicación de los drones, se podrán atender de manera acertada los riesgos de los cultivos, lo que permitirá evitar grandes pérdidas de la cosecha; asimismo, se producirán impactos de desarrollo social, económico y ambiental al atender de manera oportuna los riesgos del cultivo.

\section{Fundamentación teórica}

La productividad de un cultivo en términos biológicos comienza a definirse desde el inicio del ciclo de producción comercial y es afectada por una multiplicidad de factores, algunos de ellos propios del genotipo, otros del ambiente y otros de las condiciones de manejo. La descripción del crecimiento de una planta, o de un cultivo, a lo largo de su ciclo de vida o de producción, así como la evaluación de tratamientos capaces de modificar la acumulación de biomasa de un vegetal, requieren indicadores objetivos que puedan ser validados estadísticamente. Las técnicas de análisis del crecimiento son herramientas útiles para estos fines. Pueden aplicarse en múltiples situaciones, pero su empleo en cultivos intensivos presenta aspectos particulares y precauciones a ser tomados en cuenta, acerca de los cuales la información disponible es relativamente escasa y dispersa (Di Benedetto y Tognetti, 2016).

El estado del arte evidencia avances a lo largo de la historia en visión artificial general y visión artificial orientada a la agricultura. Además, pone en evidencia un esquema general de funcionamiento para la visión artificial, pero con diferentes métodos específicos (Betancourt, 2014). Existen diversos trabajos automatizados relacionados con el cultivo de las plantas que se dirigen a promover acciones y alternativas para el desarrollo agrícola.

En México, existen políticas públicas y programas de desarrollo que promueven la Educación Ambiental (EA); sin embargo, no se ha logrado concientizar a la población sobre la afectación a nuestro planeta. Además, hay propuestas resultados de estudios orientadas a una intervención estratégica del Estado para el fomento de la innovación y desarrollo científico y tecnológico a partir de un método neokeynesiano en la educación superior, a fin de promover una economía altamente competitiva que sugiere mejorar la administración de la investigación y el desarrollo (Cabello, 2013).

Actualmente, se tienen acciones implementadas y se difunde la información a través de las telecomunicaciones para el desarrollo tecnológico de sistemas automatizados. Uno de los principales desarrollos tecnológicos en los 
últimos tiempos es el de los llamados drones utilizados en diversas áreas como la seguridad, aplicaciones de reconocimiento automático, estudios geográficos o territoriales, el sector ambiental y la agricultura. Los drones entonces constituyen una tecnología que ayuda a los múltiples procesos de la agricultura, a captar información importante y evaluar las condiciones de los terrenos monitoreados, gracias a sus grandes ventajas para sobrevolar los campos y los cultivos, y aplicando la tecnología de cámaras realizan el recorrido de forma virtual (González, 2015).

La incorporación de la tecnología en la agricultura es percibida en menores escalas y, como resultado de ello, se desarrollan aplicaciones de software que incorporan técnicas y recursos electrónicos que optimizan el proceso del cultivo. El procesamiento digital es el conjunto de técnicas que se aplican a las imágenes digitales con el objetivo de mejorar la calidad o facilitar la búsqueda de información dentro de ella. Antes de extraer información directamente de la imagen, se acostumbra a elaborar un procesamiento previo de esta para conseguir otra que nos permita hacer el proceso de extracción de datos más sencillo y eficiente. Por ejemplo, el procesamiento puede incluir funciones para modificar la luminosidad y el contraste, para re-escalar la imagen, los niveles de color, las curvas, la binarización, el desenfoque (blur), etc. (Maduell, 2012). Un buen procesamiento de la imagen equivale a un nivel de efectividad más alto, pero no existe un método específico de visión artificial para la detección de cualquier elemento y su efectividad dependerá de un buen entrenamiento del sistema (Betancourt, 2014).

La colección de datos, normalmente denominada base de datos (BD), contiene información relevante para una empresa. El objetivo principal de un Sistema Gestor de Base de Datos (SGBD) es proporcionar una forma de almacenar y recuperar la información, de una base de datos de manera que sea tanto práctica como eficiente (Silberschatz y Korth, 2002). Los sistemas de BD realizan el procesamiento de los datos con la finalidad de generar reportes o información fácil de interpretar, la cual servirá para dar entrada a un sistema de información, o bien, ser analizada para la toma de decisiones en algún proceso o proyecto.
Uno de los trabajos que realiza el análisis de las experiencias y los principales problemas de un proyecto de desarrollo regional, que propuso establecer los lineamientos de la modernización en la agricultura, es el proceso de producción agrícola del Plan Chontalpa, Tabasco, México, 1988. Su concepción fue buscar alternativas a la crisis agrícola, la ampliación de la frontera agrícola y la colonización, y explotación de los recursos naturales del sureste. La evolución de los cultivos está relacionada con la existencia de la agroindustria estatal (ingenios) y privada, y la agroindustria de los productores (Flores, 1990).

El trabajo de automatización de sistema de riego, para el cultivo de flores tipo exportación, constituye una de las principales actividades que permite el incremento de las exportaciones en el país, sin embargo, los avances tecnológicos en este sector son muy reducidos, lo que ha conllevado a una vinculación lenta de la automatización con los procesos que hacen parte de esta área (Agudelo et al., 2005).

El trabajo de procesamiento de imágenes de plantas ornamentales multi-escala, para calcular su crecimiento, representa una herramienta de apoyo para aumentar la productividad en los viveros; para ello, se desarrolló un algoritmo para calcular el crecimiento de las plantas, se formuló una solución innovadora en el ámbito de agricultura de precisión, se procesaron las imágenes de las plantas ornamentales escalando sus dimensiones para calcular su crecimiento. En el desarrollo de este trabajo, se utilizaron tecnologías emergentes, como el algoritmo de reducción por multi-escala para procesar imágenes, el lenguaje de programación Python y la biblioteca de visión artificial OpenCV. Asimismo, se aplicó el algoritmo multiescala a muestras gráficas con diferentes proporciones de la misma imagen para obtener cálculos del crecimiento de las plantas (Cásares et al., 2017).

Otro de los estudios es el trabajo monitorización de cultivos utilizando drones, el cual considera que la agricultura mexicana actual está llena de necesidades de actualización de diversa índole. Con la tecnología dron se pretende lograr reconocimientos de espacios agrícolas para reconocimiento de plagas y para sistemas 
de rociado. La electrónica y la informática son ciencias que se combinan para conformar la tecnología dron que corresponde al mundo globalizado actual (Núñez et al., 2015).

Con la gestión de los sistemas de información automatizados que generen educación ambiental y por ende conocimiento a través de la aplicación, se contribuye con el mejoramiento de calidad de vida de las personas generando impactos de desarrollo sustentable positivos para la región (Bedolla et al., 2015).

El trabajo "reconocimiento automático de patrones para el tratamiento de información en el cultivo" propone un sistema de desarrollo con tecnología de software y recursos electrónicos que se dirige al sector agrícola con el que se puedan identificar de manera oportuna los riesgos de las plantas por posibles plagas (mosquita blanca), tipo de suelos, afectaciones por insectos, tratamientos inadecuados por el riego, entre otros riesgos que limiten su desarrollo (mancha de la hoja u hoja seca). El sistema de reconocimiento identifica hasta este momento el desarrollo óptimo del cultivo (desarrollo favorable) y alguna afectación por plaga o enfermedad (desarrollo no favorable), considerando las características físicas de las imágenes del cultivo de limón, el mango y la palmera de coco, que fueron capturadas con el dron. Mediante el sistema de reconocimiento se lleva a cabo una comparación de las características de las imágenes que se captan con el dron y los patrones de los objetos almacenados en la base de datos, aplicando algoritmos de procesamiento de imágenes, así como aplicaciones y librerías para el reconocimiento de patrones, y con base en el resultado se podrán implementar acciones que remedien esas afectaciones y/o errores en el cultivo, y por consiguiente, minimizar los riesgos de la producción en las regiones de la Costa Chica y Acapulco, Gro., México.

\section{Metodología}

En este estudio se realizó un trabajo de campo en el que se observaron e identificaron las características de algunas plantas como el limón, el mango y la palmera de coco cultivadas en la región de la Costa Chica y Acapulco del Estado de Guerrero. También se desarrolló una herramienta de software con la que se realiza el reconocimiento automático de las imágenes de los cultivos. En el trabajo de campo se tomaron fotografías de las plantas con desarrollo favorable, es decir, imágenes de cultivos que presentaban características con desarrollo óptimo; y de plantas que presentaban alguna problemática o enfermedad que afectaba su desarrollo productivo, como plagas y riesgos por insectos (mosquita blanca), así como cualquier anomalía (enfermedad de hoja seca) que pudiera afectar el progreso favorable. Estas imágenes, que fueron tomadas con la cámara del dron, fueron clasificadas de acuerdo con sus características (características de las plantas con desarrollo óptimo favorable y no favorable) y se prosiguió con su almacenamiento en una base de datos con el objeto de contar con un repositorio de imágenes que servirían para llevar a cabo la comparación con aquellas que fueran capturadas con el dron. En el proceso de identificación mediante el sistema automático se revisaron las características de las plantas, aplicando las librerías y los algoritmos de reconocimiento de imágenes. El sistema de reconocimiento realiza el procesamiento automático de comparación de las imágenes, siendo capaz de determinar resultados que dictaminan el reconocimiento de los objetos o imágenes de las plantas, y se genera también un reporte que permite informar una posible anomalía o enfermedad. Con la información obtenida a través del sistema de reconocimiento automático, se podrá atender oportunamente el problema presentado en algún cultivo.

La metodología empleada para el desarrollo del trabajo contempló técnicas y modelos de la ingeniería del software, recursos electrónicos, trabajo de campo y el análisis de la información generada con el sistema de reconocimiento de las imágenes de los cultivos (Figura 1). 


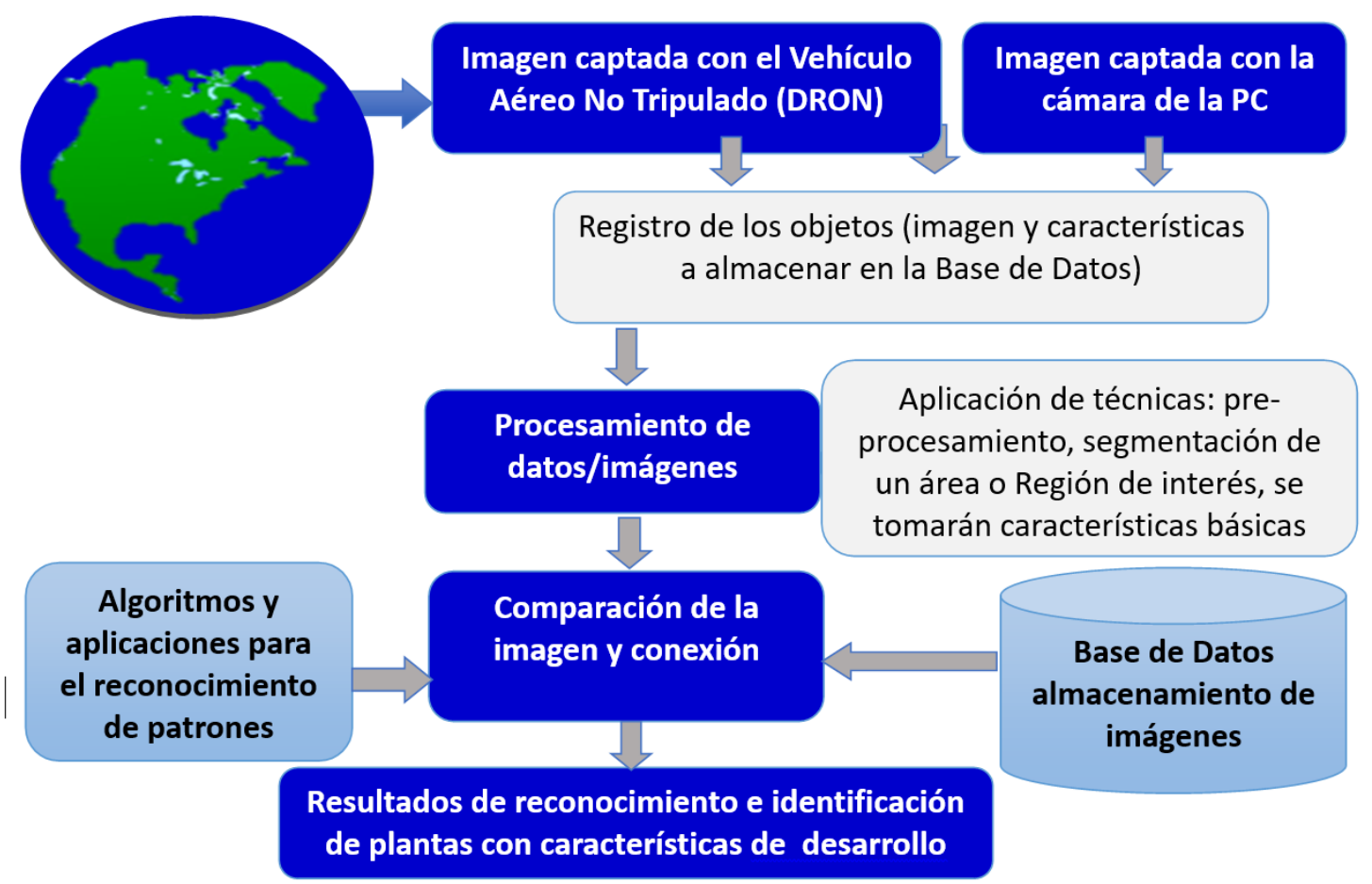

Figura 1. Metodología general, representada mediante un diagrama de bloques de las etapas que integran el sistema para el proceso de reconocimiento de patrones y características de las imágenes de plantas, así como la conexión con la Base de Datos.

En el trabajo de campo, se desarrolló un instrumento de entrevista en la que se cuestionaba información referente al conocimiento de los tipos de cultivos más comunes y sus características básicas que identifican el progreso óptimo, información de las afectaciones por plagas y enfermedades de esos cultivos, y la opinión referente al desarrollo del sistema de reconocimiento automático, que identifica el riesgo en el progreso favorable de las plantas y que se propone como una alternativa para la toma de decisiones para el desarrollo agrícola, en las regiones de Acapulco y la Costa Chica del estado de Guerrero.
La entrevista de opinión fue aplicada a informantes clave. Para ello, fueron considerados los agricultores de la región, conocedores de herramientas automatizadas, profesionales de las ciencias ambientales y personas comunes que participaron en eventos académicos de instituciones educativas y gobierno local, en los que se presentó el sistema como una propuesta automática para el desarrollo en el sector de la agricultura. Además, se llevó a cabo la captura de las imágenes de los cultivos del limón, el mango y la palmera de coco mediante el uso del recurso electrónico dron (Figura 2). 


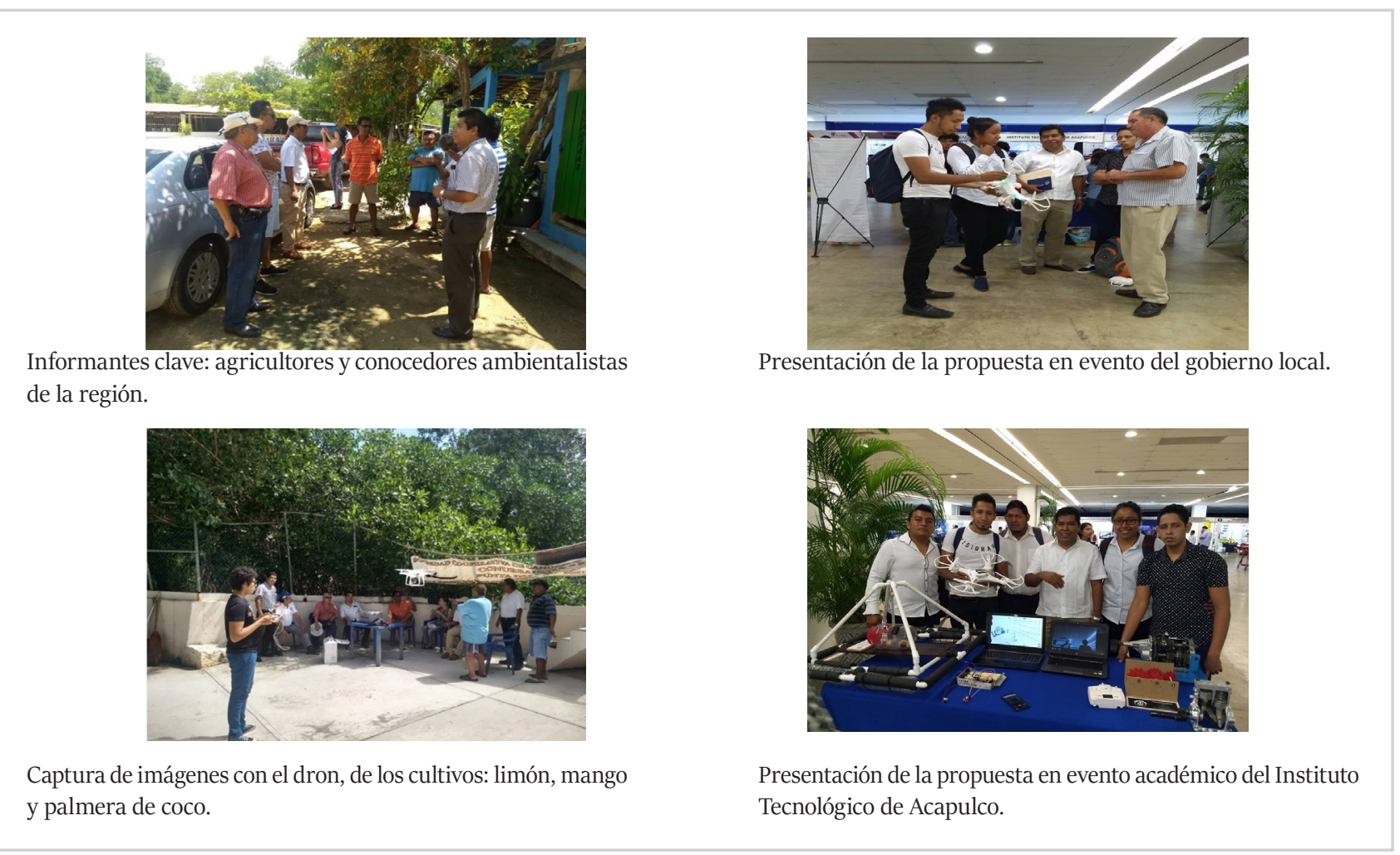

Figura 2. Trabajo de campo, se aplican entrevistas de opinión a los informantes clave; y se realiza la captura de las imágenes tomadas con el dron de las plantas de limón, el mango y la palmera de coco cultivadas en la costa de Acapulco, Gro., México.

El proceso de reconocimiento automático de las imágenes que son identificadas con características de desarrollo óptimo y favorable, y características con desarrollo no favorable por riesgo de plaga o enfermedad del cultivo, considera una serie de actividades que comienzan con el control de vuelo del dron, con la captura de las imágenes, el sistema de reconocimiento y el análisis de la información. El control de vuelo del dron se inicia con el análisis y especificaciones de funcionalidad de los componentes, en los que se contempla el tipo de cámara, las aplicaciones de software, el tiempo o duración de carga de la batería, la distancia, el control a través del dispositivo móvil, entre otras funcionalidades, y por supuesto, el manejo de este recurso electrónico.

La siguiente actividad considerada fue la captura de las imágenes desarrollada en el trabajo de campo, para la cual se dirige el recurso electrónico a los cultivos con el objeto de realizar la captura de las imágenes con la cámara del dron, y poder ser almacenadas en dispositivos de almacenamiento para su utilización en el recurso en el que se encuentra la aplicación o sistemas de reconocimiento. Las imágenes que se capturaron con el dron fueron las plantas de limón, el mango y la palmera de coco; para ello se consideraron plantas con características de desarrollo favorable y con riesgo por plaga o enfermedad. La siguiente etapa del trabajo considera el sistema de reconocimiento, el cual se construyó utilizando las técnicas de la ingeniería del software; en esta etapa se realiza el procesamiento de las imágenes contemplando la segmentación de la región de interés y el proceso de identificación, aplicando las técnicas de preprocesamiento y segmentación de un área de la planta; y haciendo uso de librerías, aplicaciones y algoritmos de reconocimiento de patrones, se realiza la comparación de las imágenes que se tienen almacenadas en la Base de Datos y las imágenes que se captaron con el dron. Por último, se realiza el análisis de la información generada de manera automática a través del sistema de reconocimiento y que presenta los resultados de las comparaciones de las imágenes de plantas; si se encuentran características similares y de patrones de riesgo, informará a través del sistema dicho 
resultado. Con ello se podrán tomar decisiones oportunas que eviten el riesgo de desarrollo y producción del cultivo en las regiones de las Costas de Guerrero.

\subsection{La población y la muestra}

La población considerada en el trabajo contempló imágenes de plantas de limón, el mango y la palmera de coco, que fueron capturadas con el dron. Las imágenes capturadas para ser almacenadas en los dispositivos de almacenamiento fueron 50 plantas con desarrollo favorable y 50 con desarrollo no favorable, siendo una población total de 100 imágenes. La muestra considerada para la realización de las pruebas fue de 24 imágenes con desarrollo favorable y 30 con desarrollo no favorable, siendo un total de 54 imágenes muestra para la realización de las comparaciones, que fueron procesadas con el sistema de reconocimiento (Tabla 1).

Tabla 1. Determinación de la población y la muestra considerada en el trabajo Reconocimiento automático de patrones y características de las imágenes de los cultivos como alternativa para el desarrollo agrícola

\begin{tabular}{|c|c|c|c|c|c|c|c|}
\hline $\begin{array}{l}\text { IP (limón, mango } \\
\text { y palmera de } \\
\text { coco) }\end{array}$ & $\begin{array}{l}\text { IP capturadas } \\
\text { con el dron }\end{array}$ & $\begin{array}{l}\text { Comparaciones realizadas } \\
\text { con el Sistema de } \\
\text { reconocimiento }\end{array}$ & No. de RF & \% RF & No de RNoF & $\begin{array}{c}\% \\
\mathrm{RNoF}\end{array}$ & $\begin{array}{c}\text { \% Total de } \\
\text { comparaciones } \\
\text { con el sistema de } \\
\text { reconocimiento }\end{array}$ \\
\hline IP-DF & 50 & 24 & 17 & $71 \%$ & 7 & $29 \%$ & $100 \%$ \\
\hline P-DnoF & 50 & 30 & 25 & $83 \%$ & 5 & $17 \%$ & $100 \%$ \\
\hline Totales & 100 & 54 & 42 & $77 \%$ & 12 & $23 \%$ & $100 \%$ \\
\hline
\end{tabular}

IP=Imágenes de Plantas; IP-DF=Imágenes de Plantas con Desarrollo Favorable; IP-DNoF=Imágenes de Plantas con Desarrollo No Favorable; $\mathrm{RF}=$ Reconocimiento Favorable; RNoF=Reconocimiento No Favorable. Fuente: Elaboración propia.

También se consideró a informantes clave, entre ellos agricultores, a quienes se les aplicó una entrevista con preguntas abiertas con el objeto de conocer los tipos de plantas frutales más comunes de la región, así como las posibles afectaciones provocadas por las plagas y enfermedades de los cultivos. Otros informantes clave fueron conocedores ambientalistas, expertos de sistemas automatizados y sociedad en general, a quienes se presentó el sistema como una propuesta automatizada con posibilidades de aportar al sector agrícola y que pudiera ser aceptada como una alternativa de desarrollo tecnológico para contribuir en el desarrollo agrícola en las Costas de Guerrero.

\section{Resultados}

Los resultados obtenidos en el proyecto que considera el sistema de reconocimiento automático demostraron deducciones favorables, ya que las imágenes que fueron comparadas aplicando el procesamiento automatizado a través de la herramienta, pudieron ser identificadas de manera satisfactoria. El desarrollo de este proyecto que contempla las tecnologías de la información y comunicación, y que se propone como una alternativa para el desarrollo agrícola, realiza el procesamiento automático y se genera la información con la que se identificarán características o patrones de los riesgos de los cultivos. Con esta información generada de manera automática, se amplían las posibilidades de tomar las mejores decisiones para una atención oportuna. En esta propuesta automática se llevaron a cabo las comparaciones de las imágenes que fueron captadas con el dron (54 comparaciones de cultivos de limón, mango y 
palmera de coco) y de acuerdo con las características de los objetos almacenados en la Base de Datos, se obtuvo como resultado de identificación favorable el $71 \%$, es decir, el sistema pudo reconocer las imágenes con un progreso óptimo en su desarrollo; y el 83\% de identificación no favorable, es decir, se reconocieron las imágenes con algún tipo de riesgo por plaga o enfermedad en un $83 \%$. De acuerdo con las pruebas preliminares, el sistema fue capaz de identificar las características básicas que describen el desarrollo óptimo del cultivo, y los patrones derivados por los riesgos ocasionados por la plaga o enfermedad que obstaculizan el desarrollo favorable de la planta. El sistema también es capaz de generar los reportes y el tratamiento de información de la Base de Datos que dirige a la toma de decisiones, con lo que se abre la posibilidad para atender los riesgos causados por la plaga de la mosquita blanca y la enfermedad de la hoja seca de los cultivos de manera adecuada.

En la Figura 3 se señalan imágenes de los cultivos de palmera de coco y el mango, que fueron capturadas con el dron durante el trabajo de campo y almacenadas posteriormente en la Base de Datos del sistema de reconocimiento automático de patrones y características; y en las que se identifican la forma de la planta, el color, el contorno, la densidad, el riesgo, entre otras características consideradas para realizar la comparación.

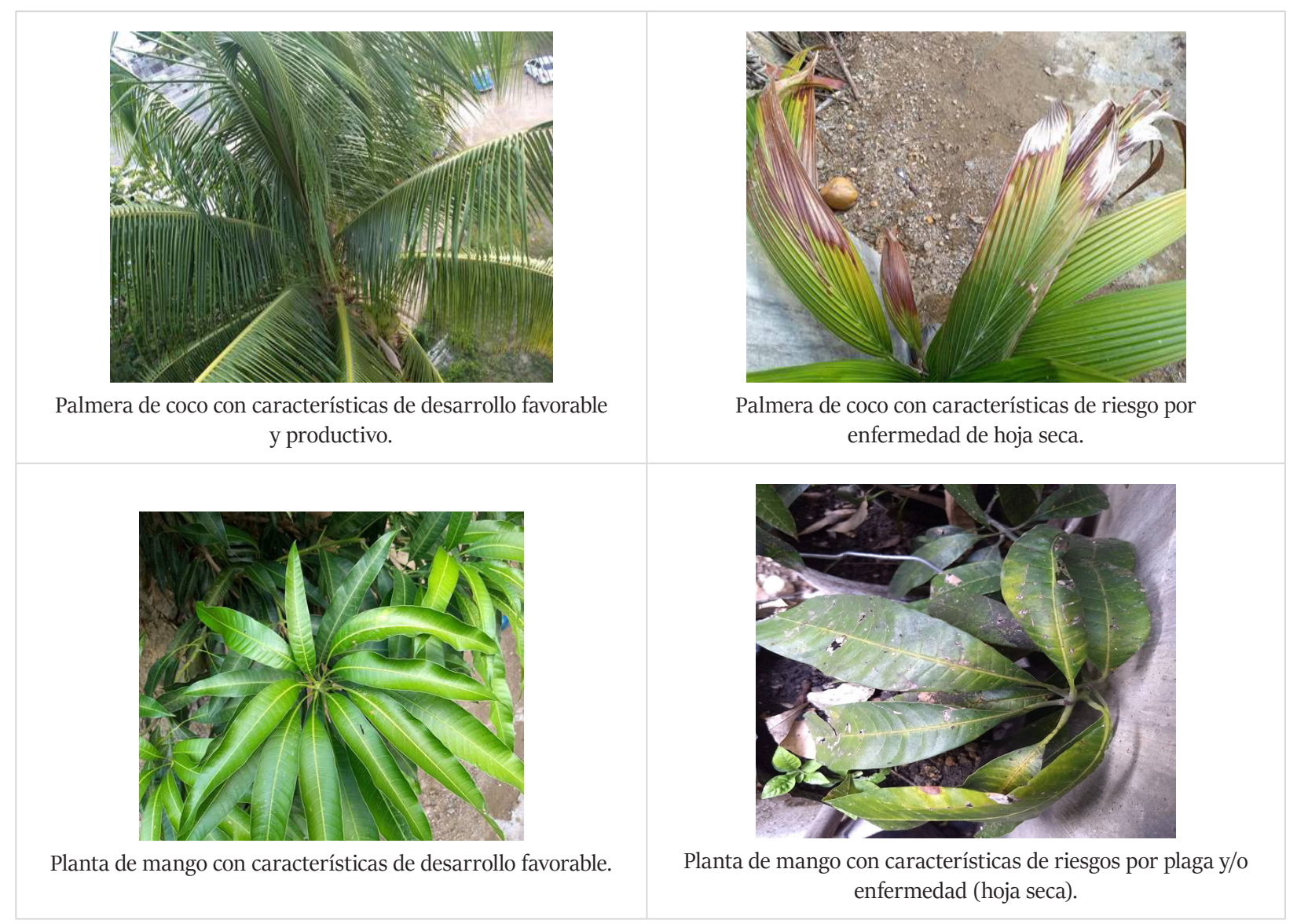

Figura 3. Plantas endémicas (palmeras de coco y el mango con diferentes estados) de Acapulco y la Costa Chica del estado de Guerrero, México. Análisis de campo y pruebas de sistema, 2018. 
Para seleccionar las imágenes de pruebas, se llevó a cabo un estudio de campo en el que se analizaron las imágenes a contemplar. En este análisis observacional y de entrevista con agricultores de la región, se identificaron plantas con desarrollo favorable y no favorable, las imágenes fueron captadas con la cámara del dron y de acuerdo con la selección de estas imágenes, se llevó a cabo el registro en el sistema automático para su almacenamiento en la base de datos.

Las imágenes almacenadas en la base de datos fueron consultadas electrónicamente y comparadas con las imágenes captadas por el dron mediante algoritmos de procesamiento y selección de características. Los resultados de las comparaciones de estas imágenes generaron un reconocimiento favorable de identificación de las características de las plantas comprendido entre el $71 \%$ y el $83 \%$.

En la Figura 4 se señalan las imágenes almacenadas en la base de datos, las cuales fueron utilizadas en las pruebas preliminares para el procesamiento y selección de características mediante algoritmos de reconocimiento de patrones.

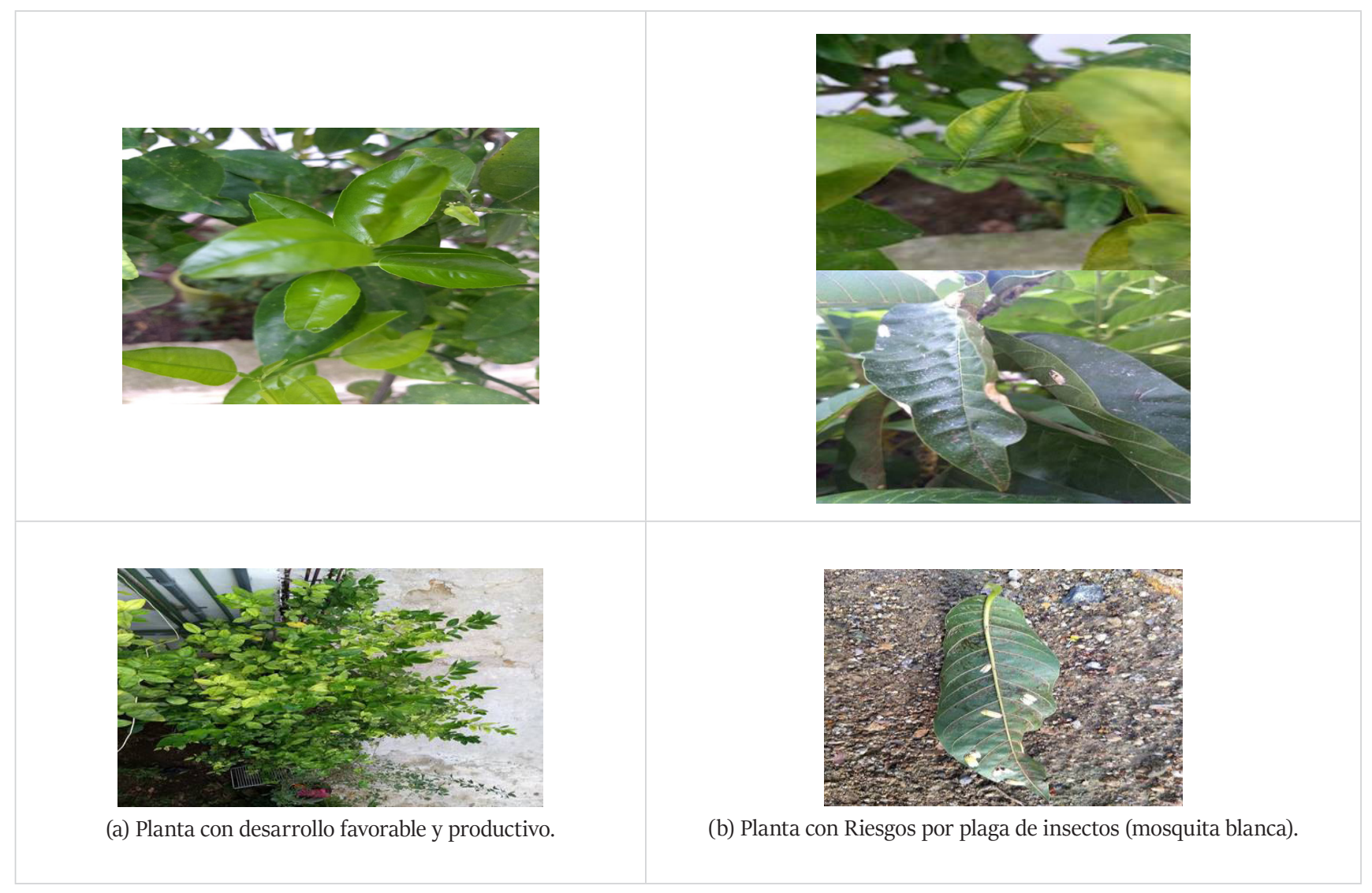

Figura 4. Plantas endémicas (limón) de Acapulco y la Costa Chica del estado de Guerrero, México, Análisis de campo y pruebas de sistema, 2018. 
En la Figura 5 se llevó a cabo la comparación de una imagen de una planta de limón con riesgos por plaga y/o enfermedad de hoja seca (enfermedad causada por tipo de suelo, de acuerdo con la información de informantes clave), que demostró, a través del sistema el reconocimiento automático de patrones con el riesgo de plaga (mosquita blanca), un $71 \%$ de identificación.
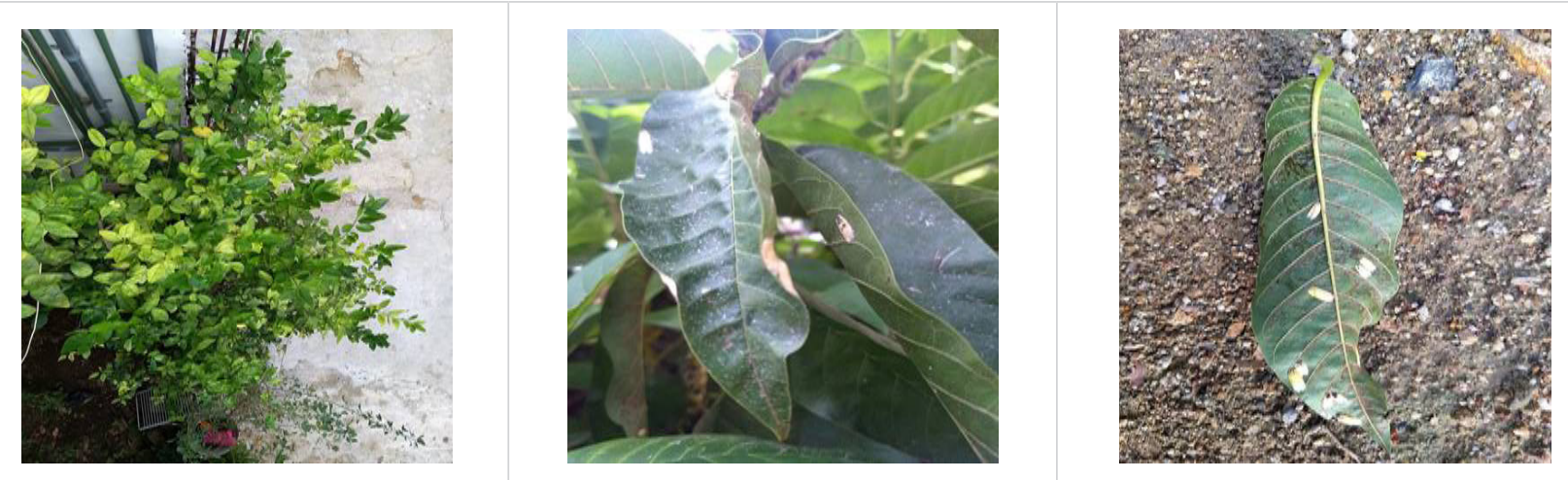

Figura 5. Comprobación de patrones de una imagen de planta de limón con riesgo por plaga (mosquita blanca) endémica de Acapulco, Guerrero, México.

La aplicación automatizada contempla en su primera fase de desarrollo cuatro apartados de operación o secciones de trabajo: registro de las imágenes (captura de los objetos a almacenar en la Base de Datos), comparaciones (transacción o proceso comparativo mediante algoritmos y aplicaciones de reconocimiento), ver imágenes (listado de los registros almacenados en la base de datos), y reportes (informe de resultados de las comparaciones de las imágenes realizadas con el sistema). La evaluación del desempeño del sistema de reconocimiento se realizó tomando como muestra las imágenes de los cultivos del limón, el mango y la palmera de coco, que representan los cultivos fundamentales de las costas de Guerrero, México.

La Figura 6 presenta la sección de trabajo ver imágenes, que corresponde a visualizar los registros almacenados en la base de datos del sistema de reconocimiento y se contemplan también algunas de las operaciones básicas, como modificar la información y eliminar registros de la BD.

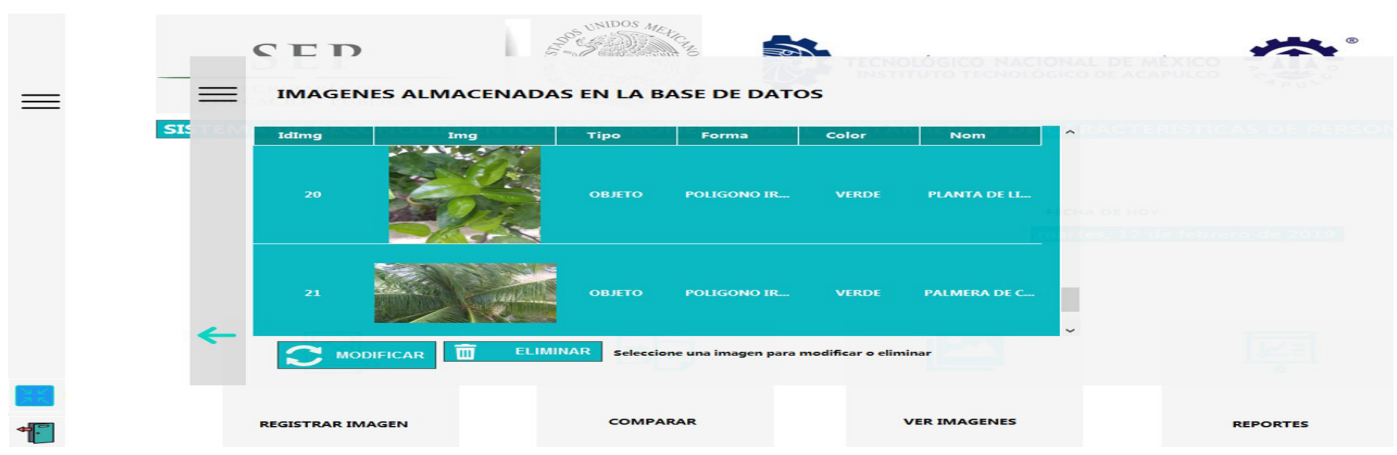

(a) Registros de imágenes de limón y palmera de coco con características básicas almacenadas en la base de datos del sistema de reconocimiento. 


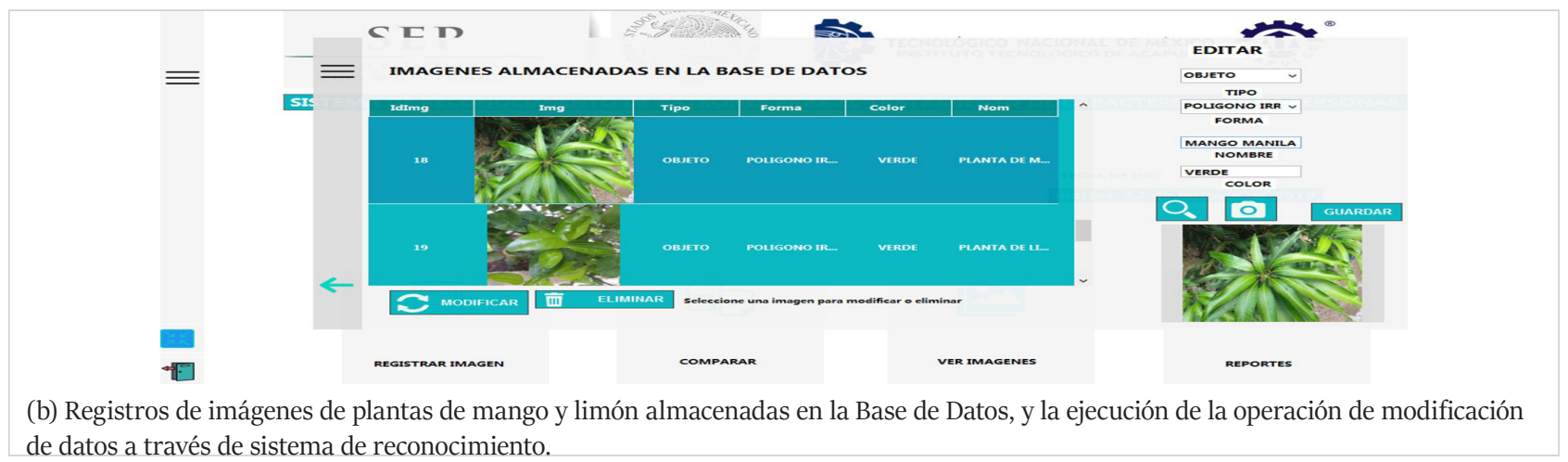

Figura 6. Ejecución de la sección de trabajo: ver imágenes para la base de datos del sistema de reconocimiento automático.

En la Figura 7 se muestra el sistema de reconocimiento, en el que se realiza de manera automática el proceso de identificación de las plantas. En el proceso de comparación a través de la aplicación se comparó una imagen de planta de mango con las imágenes almacenadas en la Base de Datos, generando como resultado preliminar una similitud de identificación con una planta de limón, la cual, por sus características de acuerdo con el color, forma, el tamaño de la imagen y prioridad de almacenamiento en la Base de Datos, contempló la mayor coincidencia y consideró que ambas plantas guardaban cierta similitud. En la siguiente transacción de la ejecución del sistema de reconocimiento se realizó la comparación de las mismas imágenes de plantas, y al realizar el procesamiento, se generó como resultado un $59.27 \%$ de coincidencia entre las imágenes.

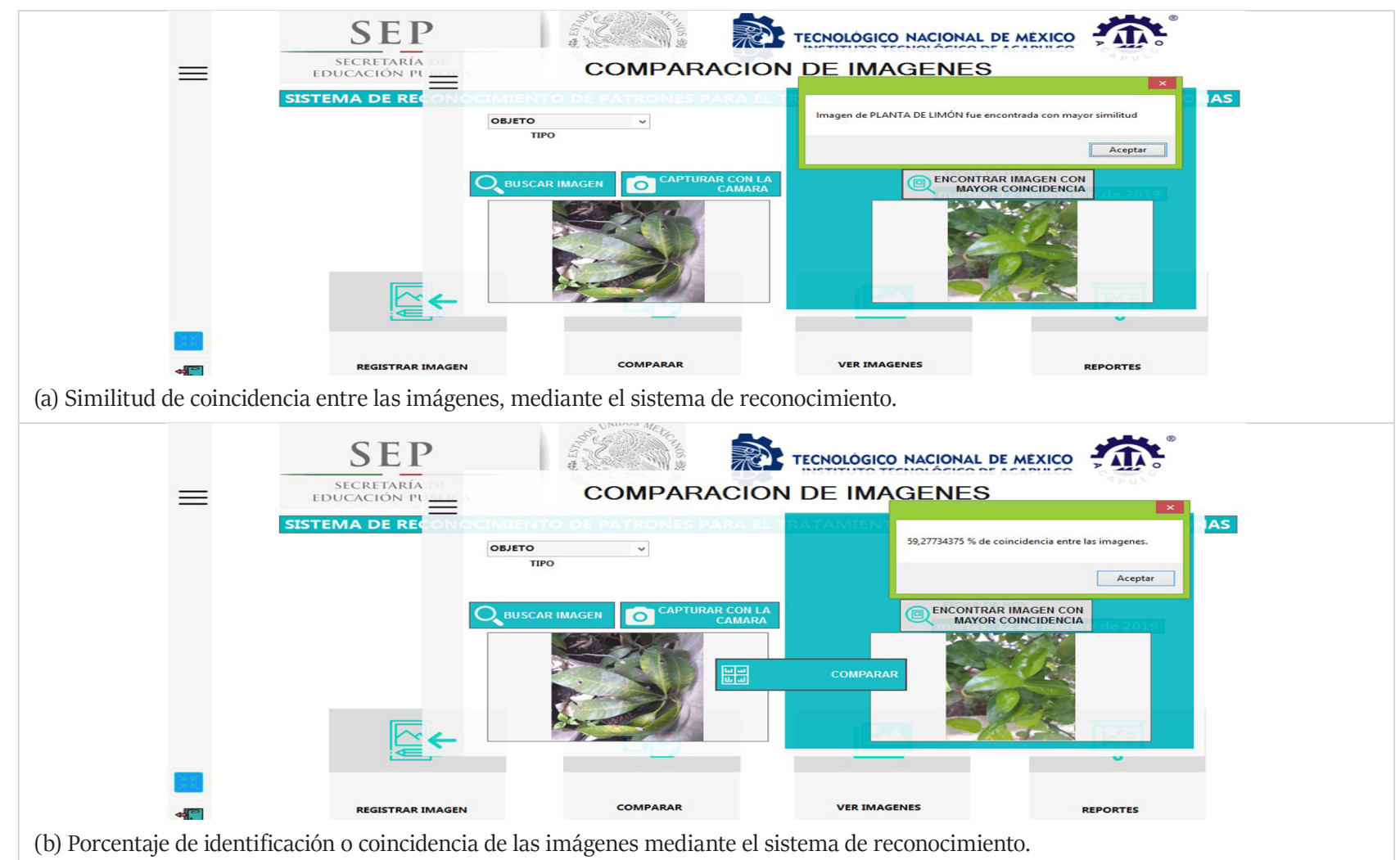

Figura 7. Sección de trabajo: comparaciones del sistema de reconocimiento automático de patrones y características en el cultivo. Ejecución de la aplicación. 
Como se puede observar en la figura anterior, el reconocimiento entre las plantas, que se genera a través del sistema no es favorable, ya que las características de las plantas generaron confusión durante el proceso automático de identificación, y debido a las características básicas similares que se registraron. Sin embargo, en una segunda evaluación con otro cultivo, se realizó la comparación de una imagen perteneciente a una palmera de coco, y al realizar el procesamiento de búsqueda en la base de datos encontró una imagen que tenía las mismas características, reconociendo una mayor similitud y coincidencia del $100 \%$ entre las imágenes con desarrollo favorable (Figura 8).

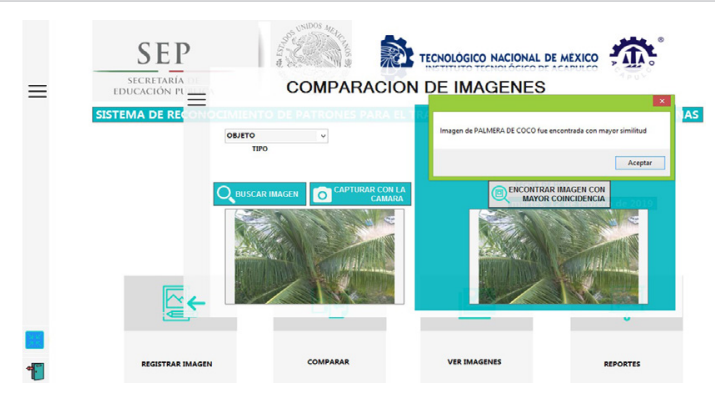

(a) El proceso de comparación entre las imágenes de palmera de coco generó como resultado la mayor similitud.

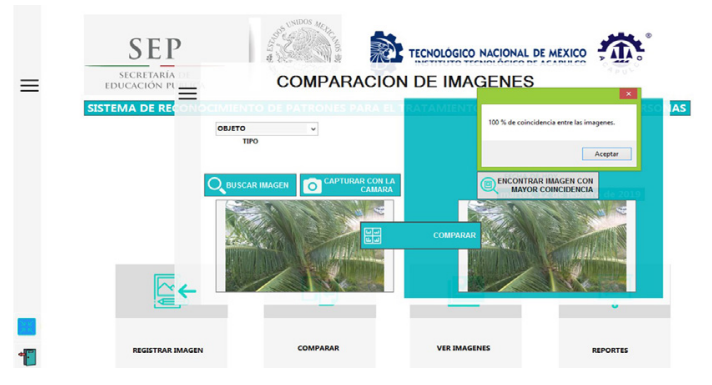

(b) El proceso de identificación entre las imágenes de palmera de coco generó como resultado el 100\% de identificación o coincidencia de las imágenes.

Figura 8. Pruebas de desempeño a través de la plataforma de trabajo del sistema de reconocimiento automático de patrones y características de las imágenes de los cultivos como alternativa de desarrollo agrícola.

Los resultados preliminares demostraron que la efectividad del reconocimiento de las características de las imágenes con desarrollo favorable fue en promedio del $71 \%$, mientras que la identificación de las plantas con desarrollo no favorable o con alguno de los riesgos por plaga o enfermedad fue $83 \%$.

La opinión de los informantes clave contempla que una propuesta de aporte a la agricultura con tecnologías innovadoras amplía las posibilidad para el desarrollo agrícola que beneficia a los agricultores y el gobierno, ya que este tipo de sistemas automatizados permiten generar reportes rápidos, que apoyan en la toma de decisiones para atender oportunamente los riesgos ocasionados por las plagas y enfermedades de las plantas, con lo que se contribuirá con el crecimiento productivo y económico del estado de Guerrero.

\section{Conclusiones}

La incorporación de sistemas automatizados dirigidos al sector agrícola incrementará las posibilidades de producción y de desarrollo de las plantas. Con el uso de los sistemas innovadores se generan los informes de interés y se dirige la atención a alternativas para apoyar la toma de decisiones.

El reconocimiento automático de patrones y características en las imágenes de los cultivos es una alternativa de innovación provechosa para el desarrollo de las plantaciones agrícolas que incrementa las posibilidades de producción, y que ofrece una estrategia con la que se identifican los posibles riesgos por plagas y enfermedades de las plantas.

El estudio ofrece una alternativa automatizada para los agricultores y el gobierno, ya que se propone para identificar y disminuir los riesgos o enfermedades de las plantas del limón, el mango y la palmera de coco, y de esta manera iniciar acciones y estrategias oportunas 
que ayuden a corregir los problemas o deterioros de la producción agrícola y, por consiguiente solucionar la problemática identificada.

En las Costas del estado de Guerrero, México, la vinculación del sector agrícola es mínima, por lo que hace falta desarrollar proyectos o sistemas automatizados dirigidos al campo que atiendan los peligros o enfermedades de los cultivos en las comunidades y busque el incremento de la producción y el desarrollo favorable.

Este trabajo pretende la apertura de un margen de estudio a investigadores del área para que enfoquen su interés en proyectos dirigidos al reconocimiento de patrones de los cultivos para que se potencien los estudios del sector agrícola, y a través de la innovación enfrentar los problemas que obstaculicen el desarrollo de los plantíos.

\section{Bibliografía}

Agudelo, R., Castellanos, D. y Medina, M. (2005). Automatización de Sistema de Riego para el cultivo de flores tipo exportación. (Tesis de Licenciatura). Facultad de Ingeniería Electrónica, Bogotá D.C. Colombia.

Bedolla, J., Bedolla, R. y Palacios, R. (2015). Sistema de Gestión de Programas de Educación Ambiental, una aplicación para el desarrollo comunitario. $20^{\circ}$ ENCUENTRO Nacional sobre Desarrollo Regional en México. Publicado In: Pasado, presente y futuro de las regiones en México y su estudio. (ISBN: 978-607-96649-1-6 UNAM-IIEc: 978-607-02-7436-7: Cuernavaca, Morelos: 17 al 20 de noviembre de 2015). México: AMECIDER, $1-24$.

Betancourt, D. (2014). Sistema de visión por computador para detectar hierba no deseada en prototipo de cultivo de frijol usando ambiente controlado. (Proyecto de grado). Universidad Católica de Colombia. Facultad de Ingeniería. Programa de ingeniería electrónica y telecomunicaciones. Bogotá D.C. Colombia.
Cabello, A. y Ortiz, E. (2013). Políticas públicas de innovación tecnológica y desarrollo: teoría y propuesta de educación superior. Revista: Convergencia Revista de Ciencias Sociales Scielo, 20(61), 135-172.

Cáceres, C. (2015). Procesamiento de imágenes para reconocimiento de daños causados por plagas en el cultivo de Begonia semperflorens (flor de azúcar). Acta agronómica. Palmira, Colombia. Universidad Nacional de Colombia. Disponible en: http://www.redalyc.org/pdf/1699/169940048012. pdf. doi: http://dx.doi.org/10.15446/acag. v64n3.42657. Acceso: julio 28 de 2019.

Cásares, C., Farías, N., García, N. y García, A. (2017). Procesamiento de imágenes de plantas ornamentales multi-escala para calcular su crecimiento. Revista: 3 C TIC: Cuadernos de desarrollo aplicados a las TIC, 6(3): 10-25.

Di Benedetto, A. y Tognetti, J. (2016). “Técnicas de análisis de crecimiento de plantas: su aplicación a cultivos intensivos". Revista: Revista de investigaciones agropecuarias: RIA, 42(3): 258-282.

Flores, A. (1990). "La modernización de la agricultura en el trópico húmedo mexicano: veinte años de experiencia en la Chontalpa, Tabasco". Revista: Revista de Geografía Agrícola, 1(1): 105-115.

González, A., Amarillo, G., Amarillo, M. y Sarmiento, F. (2015). "Drones aplicados a la agricultura de precisión”. Revista: Revista especializada en ingeniería, 10(2016): 23-37.

LAVIDA. (2012). México Rumbo a la Sustentabilidad: 40 Propuestas para la Administración Federal 2012-2018. México: La Asamblea Veracruzana de Iniciativas y Defensa Ambiental. Disponible en: https://www.lavida.org.mx/documento/ m\% $3 \%$ A9xico-rumbo-sustentabilidad40-propuestas-administraci $\% \mathrm{C}_{3} \% \mathrm{~B} 3 n$ federal-2012-2018. Acceso: 03 de abril de 2018. 
Maduell, E. (2012). Visión artificial. PID_o0184756, v.3.o. Barcelona, España: Universitat Oberta de Catalunya UOC. 1-30.

Murray, T. G., y Murray, P. G. (2012). Clima desbocado. ¿Cómo ves?. México: Guía del maestro www. comoves.unam.mx. Disponible en: http://www. comoves.unam.mx/assets/revista/168/climadesbocado.pdf. Acceso: 24 de agosto de 2018.

Noda, K., Ezaki, N., Takizawa, H., Mizuno, S. y Yamamoto, S. (2006). Detection of plant saplessness with image processing. International Joint Conference SICE-ICASE, 4856 - 486 o.

Núñez, O., Figueroa, T. y De Jesús, A. (2015). Monitorización de Cultivos Utilizando Drones. Lagunas, El Barrio de la Soledad, Oaxaca: Centro Educativo Cruz Azul, A.C. México. Disponile en: http:// vinculacion.dgire.unam.mx/vinculacion-1/ Congreso-Trabajos-pagina/Trabajos-2015/ Ciencias-fisicomatematicas/Fisica/13.\%20 CIN2015A20121.pdf. Acceso: 03 de octubre de 2018.

Plan Nacional de Desarrollo. (2013-2018). Igualdad de oportunidades para un México próspero. México: Gobierno de la República. Disponible en: http:// pnd.gob.mx. https://observatorioplanificacion. cepal.org/sites/default/files/plan/files/ MexicoPlanNacionaldeDesarrollo20132018.pdf. Acceso: 03 de abril de 2018.

Silberschatz, A. y Korth, H. (2002). Fundamentos de Bases de Datos, 4ta Edición. Madrid, España: McGRAWHILL, 787, 1-16.

Yan, L., Chunlei, X. y JangMyung, L. (2009). Visionbased pest detection and automatic spray of greenhouse plant. IEEE International Symposium on Industrial Electronics, 920 - 925. 